\title{
O DISCURSO SOBRE AS CIÊNCIAS E AS ARTES DE JEAN- JACQUES ROUSSEAU: AMBIGUIDADES E POLARIDADES ENQUANTO PRINCÍPIO DA REFLEXÃO
}

\author{
Arlei de Espíndola ${ }^{1}$
}

\begin{abstract}
Resumo:
Busco neste artigo, na tentativa de mostrar o valor teórico do Discurso sobre as ciências e as artes (1749), indicar que ele se constitui por ambiguidades e contradições muito bem medidas, envolvendo isso a: moral, ética, política, economia, metafísica, religião, filosofia, estética, etc. Ao supor a necessidade de estudar o homem visando conhecer sua natureza mais profunda, Rousseau reconhece a complexidade do trabalho científico e filosófico, identificando que tudo é formado por pares de opostos carregando perdas e ganhos, especialmente quando estão em jogo avanços, progressos, implementações. Mas isso não significa que Rousseau reivindica um movimento no sentido de apreender-se o homem sendo eternizado no seu ponto de partida. Perseguindo o prognóstico, indo além, pois, de uma mera detecção da fonte dos males, diz ele ser preciso acomodar-se as empresas humanas aos ditames da natureza de modo a aproximar-se o homem da posição mais equilibrada possível, deixando-o no lugar que lhe cabe. Tal ensinamento do Discurso em questão, antecedido de suas articulações polarizadas, peculiares e intrigantes, estabelece a riqueza que lhe é inerente, colocando-o na esfera de germe do pensamento de Rousseau.
\end{abstract}

Palavras-chaves: Antropologia. Conhecimento. Progresso. Virtude. Liberdade.

\section{THE DISCOURSE ON THE SCIENCES AND ARTS BY JEAN- JACQUES ROUSSEAU: AMBIGUITIES AND POLARITIES AS A TOPIC OF REFLECTION}

\begin{abstract}
:
In an attempt to show the theoretical value of the Discourse on the sciences and arts (1749), this article seeks to indicate that it is constituted by ambiguities and contradictions very well measured, involving moral, ethics, politics, economics, metaphysics, religion, philosophy, aesthetics, etc. In assuming the need to study man in order to know his deepest nature, Rousseau recognizes the complexity of scientific and philosophical work, identifying that everything consists of pairs of opposites bearing losses and gains, especially when advances, progress, and implementations are at stake. But this does not mean that Rousseau claims a movement in the sense of apprehending man being eternalized at his point of departure. Pursuing the prognosis, going beyond a mere detection of the source of evils, he says that it is necessary to accommodate human enterprises to the dictates of nature in order to approach man from the most balanced position possible, leaving him in his proper place.This teaching of the Discourse in question, preceded by its polarized, peculiar and intriguing articulations, establishes its inherent richness, placing it in the rudiments sphere of Rousseau's thought.
\end{abstract}

Key words: Anthropology. Knowledge. Progress. Virtue. Freedom.

1 Doutor em Filosofia pela Universidade Estadual de Campinas - UNICAMP/SP, com estágio pósdoutoral em Filosofia na Pontifícia Universidade Católica do Rio Grande do Sul - PUC/RS. Professor da Graduação e Pós-Graduação (Stricto Sensu) em Filosofia da Universidade Estadual de Londrina UEL/PR. E-mail: earlei@uel.br 
O estabelecimento da relação entre o ser humano e o âmbito da ciência, do conhecimento, da cultura, evidenciando-se o progresso, permite notar-se um impacto que atinge diferentes planos, indo do íntimo daquele à vida comunitária. Cabe perguntar se o Discurso sobre as ciências e as artes, texto de Rousseau que seria premiado em 1750, na cidade de Dijon, salientará a esfera moral. É claro, no geral, que a prevalência vem recair, neste trabalho ao qual nos propomos a analisar, "sobre as ciências e as artes e sua influência moral sobre a humanidade" (WOKLER, 1995, p. 18), ainda que exista outras órbitas podendo ser influenciadas alternadamente; e isso dada a ordem de valor que possuem, fazendo a totalidade tornar-se algo como um corpo vivo em movimento, recebendo ou difundindo luzes de diferentes lados.

Talvez possamos apostar que é a força da contingência, da ocasião, que leva o pensador de Genebra a destacar o plano moral inicialmente, na relação que citamos no começo do texto; quem sabe essa referência introdutória, destacando aquele âmbito, signifique um recurso didático de que Rousseau se utiliza. $\mathrm{O}$ efeito daquele comércio, ao invés da esfera moral, poderia encontrar, por exemplo, o campo: ético, político, estético, econômico. Se olharmos tal relação, considerando cada uma dessas órbitas, ora citadas, a seu tempo, por diferentes ângulos, entenderemos que o destaque do plano moral pode mesmo significar um artifício didático. Pois tudo, em partes, é entrelaçado, de modo que tanto um fator às vezes é causa dos fenômenos como às vezes é consequência, se não incorremos obviamente no dogmatismo; aliás, não será esse o caso daqueles que concedem exclusividade, por exemplo, ao fator econômico, vendo-o como essencial na explicação das coisas do mundo? Pretendo mais para frente retratar, aqui, esta aludida circularidade a fim de esclarecer do porquê o Primeiro Discurso exige maior consideração do público na filosofia de Rousseau no seu conjunto.

Agora com a pergunta, formulada para o concurso de 1749, remetendo-se em primeiro lugar à esfera moral, o que deseja saber a academia de Dijon? Será indicar que o "renascimento" das ciências e das artes contribuiu para aprimorar os costumes? É intrigante, exercendo fascínio e espanto no público esclarecido especialmente, que Rousseau assume, ao buscar resolver essa questão, um partido voltado para a direção da negativa. Tomado pelo anseio de referendar seu pensamento, o autor argumenta, valendo-se de um tom conclusivo, mas sem recusar o nexo de causalidade: "onde não existe nenhum efeito não há nenhuma causa a procurar; nesse ponto, porém, o efeito é

\begin{tabular}{|l|l|l|l|l|}
\hline Qevista Dialectus & Ano 5 & n. 12 & Janeiro - Julho 2018 & p. 327-339 \\
\hline
\end{tabular}


certo, a depravação é real, e nossas almas se corromperam à medida que nossas ciências e nossas artes avançaram no sentido da perfeição" (OC III, Discours sur les sciences et les arts, 1964, p. 9).

O pensador genebrino inaugura uma orientação própria, em certa medida, ao colocar em xeque a devoção característica da maioria dos grandes filósofos do iluminismo no seu quadro geral. Sabe-se que Diderot, d'Alembert, Voltaire, Montesquieu, dentre outros, julgam de uma forma diferente o que precede; eles defendem as ciências, as letras, as artes, a filosofia, tendo-as enquanto fontes precípuas de avanços, riquezas, crescimento, e produção da liberdade. Para esses últimos, é sem sentido, pois, condenar as Luzes e o universo da cultura.

É impossível não reconhecer a quantidade de passagens do Primeiro Discurso prestando-se a revelar um Rousseau polêmico, apologista da ignorância, primitivista, ou voltado ao afã de regressar ao passado, a qual é de fato grande. Logo no prefácio do seu escrito nosso autor admite pôr-se, com sua conduta, a ferir "tudo o que constitui, atualmente, a admiração dos homens" (idem, p. 3) certo, entretanto, de que sofrerá "uma censura universal" (Idem, ibidem). Mais à frente, na introdução, o pensador franco-suíço é explícito ao entender, imprimindo uma solução inicial ao impasse em jogo, que sua escolha teórica não visa alimentar ideias condenáveis que freiem ou retirem as chances de o mérito humano ser considerado. Eis que escreve JeanJacques: "Não é em absoluto a ciência que maltrato, disse a mim mesmo, é a virtude que defendo perante homens virtuosos" (Idem, p. 5). E a virtude, como se tem ciência desde Sêneca, com suas Cartas a Lucílio, é resultado do trabalho, do empenho, do esforço.

O homem em consequência da natureza que possui, mais complexa, aliás, que a dos diversos bichos conhecidos, convive com necessidades espirituais que carecem de ser satisfeitas. Descartes, fonte de leitura, e de inspiração às avessas, de nosso autor, diferencia o homem dos animais e indica que a necessidade espiritual é suprida ao ser obtido conhecimento na medida em que este conduz o primeiro ao caminho da sabedoria. Ora, assim é encontrado, segundo Descartes, o verdadeiro alimento de que aquele carece, tendo este a ver com "conhecimento", e não outro objeto. E por esse motivo: “os homens, cuja parte principal é o espírito, deveriam

\begin{tabular}{|c|c|c|c|c|}
\hline Rovita Dialectus & Ano 5 & n. 12 & Janeiro - Julho 2018 & p. $327-339$ \\
\hline
\end{tabular}


empregar os seus principais cuidados na procura da sabedoria, que é o seu verdadeiro alimento" (DESCARTES, 1953, p. 558-559). ${ }^{2}$

Ponto pacífico é de que o homem tem seu lado espiritual, seu mundo interior, composto por sua consciência no sentido rousseauniano, sua sensibilidade, e também sua racionalidade, que necessitam do suprimento imaterial, abstrato. Entende-se que há duas dimensões antropológicas, razão pela qual é compreensível, todavia, que o ser humano exercite sua racionalidade, satisfazendo seu lado prosaico, como o considera Edgar Morin recentemente, praticando o pensamento abstrato, o cálculo, a lógica; mas é natural que atenda seu lado poético por outro lado, como também diz Morin, procurando saciar-se com o canto, com a música, com a dança, enfim, que não tema, de forma alguma, suas emoções. Quer dizer, voltando-se já a Rousseau, o homem não está limitado em precisar satisfazer faltas materiais, fisiológicas ou orgânicas, como acontece com as bestas, e sua atmosfera deve ser entendida como coisa que ultrapassa a dimensão epistemológica, chegando a um campo mais amplo, culminando no âmbito metafísico. Conclusivamente, diz Rousseau: "Como o corpo o espírito tem suas necessidades. Estas são o fundamento da sociedade, aquelas constituem seu deleite" (OC III, Discours sur les sciences et les arts, 1964, p. 6). ${ }^{3}$

O olhar sobre o tema do fomento ou recepção das ciências, das letras, das artes, e da filosofia, por parte do filósofo de Genebra, notadamente, é ambíguo, dúbio, multifacetado. E cultivá-las ou acolhê-las significa criar condições da mesma forma para atingir-se a virtude, não representando isto conivência, necessariamente, com os vícios, com a corrupção moral. Em suma, dentre as alternativas resultantes de seu desenvolvimento podem se apresentar tanto vicissitudes quanto disposições virtuosas.

Para a relação de Rousseau com Descartes, próxima teoricamente, mas controversa, leia-se: BEAULAVON, Georges. La philosophie de J.-J. Rousseau et l'esprit cartésien, Revue de Métaphysique et de Morale, Paris, Librairie Armand Colin, 1937.

Ao pensar-se no homem e nas necessidades do espírito humano é preciso levar-se em conta a amplidão da natureza deste que o faz constituído por duas dimensões, além da esfera corporal, às quais associam-se ao âmbito prosaico, mas também ao poético. Edgar Morin indica-nos, sem ser um comentador de Rousseau, que a prosa e a poesia são mais do que duas formas literárias, fazendo-se duas coisas antropológicas: "O prosaico é tudo o que concerne à técnica, à prática, aos cálculos racionais. O poético se refere à emoção, ao êxtase, à música, à poesia, ao amor, à bebida" (MORIN, E. A construção da sociedade democrática após a queda do socialismo dito real e o papel da educação e do conhecimento para a formação do imaginário do futuro, Trad. de Ester Grossi, Texto apresentado: Seminário Internacional Sobre Aprendizagem; Construtivismo Pós-Piagetiano, Porto Alegre/RS, 05 a 08 de dezembro, Promoção: UFRGS, PUC, GEEMPA e MEC, 1992, p. 15). Tem-se concedido primazia ultimamente ao que se liga ao prosaico, ao que diz respeito ao racional, esquecendo-se da dimensão poética, da esfera sensitiva do ser humano. Mas é necessário caminharmos na direção contrária se desejamos contribuir para o equilíbrio geral.

\begin{tabular}{|l|l|l|l|l|}
\hline Q Rovista Dialectus & Ano 5 & n. 12 & Janeiro - Julho 2018 & p. 327-339 \\
\hline
\end{tabular}


Isto é, o homem tanto é capaz de erros, equívocos, quanto acertos, descobertas, consolidando, portanto, triunfos, glórias, sucessos, enfim, o completo êxito.

Mas se é indicado abrir-se concessão dizendo que Rousseau julga negativamente as luzes em alguma medida, é preciso frisar que sua reticência é apenas quanto a um certo tipo de cultura, a cultura que não soma, não esclarece, mas sim divide, desorienta, confunde. Cabe lembrar, com Robert Wokler, que o Discurso sobre as ciências $e$ as artes é "ornado com [...] floreios meramente retóricos" (1995, p. 56) constituindo-se tal coisa em aspecto que serve de entrave para quem se dispõe interpretá-lo corretamente.

Ora, a vida não é facilitada, na relação com o escrito de Rousseau, com uma indicação como esta que nos fornece Wokler. Para ilustrar o grau do problema, atentemo-nos ao pequeno extrato seguinte do livro intitulado Anti-dühring escrito por Engels na segunda metade do século XIX visando refutar a ironicamente chamada 'filosofia da realidade' do senhor Eugen Dühring. Esse não é um comentário exatamente ao Primeiro Discurso mas bem serve para este fim específico enquanto professa uma filosofia da história e um dado entendimento sobre a liberdade humana:

\begin{abstract}
A liberdade consiste, portanto, no domínio sobre nós mesmos e sobre a natureza exterior baseado no conhecimento das necessidades naturais; desse modo, é necessariamente um produto do desenvolvimento histórico. Os primeiros seres humanos a se separarem do reino animal foram, em todos os aspectos essenciais, tão carentes de liberdade quanto os próprios animais; porém, todo progresso cultural foi um passo rumo à liberdade (ENGELS, 2015, p. 146).
\end{abstract}

Complica-se a linha de raciocínio do Primeiro Discurso ao lhe avaliarmos a partir de um texto como esse de Engels, o qual mostra cultivar uma convicção que é comum, bem próxima, inclusive, a de um filósofo iluminista; e sem manter o espírito de um dialético.

E o fragmento, num especulador que até é receptivo a nosso filósofo noutros escritos, revela o ponto exato do distanciamento entre o marxismo e Rousseau. Engels, defendendo a liberdade moral ou social, advoga em favor do progresso, tendo o comércio, a indústria, a produção em sentido amplo enquanto algo necessariamente positivo. Entretanto Rousseau grosso modo, no lugar onde firma ruptura com os enciclopedistas, que se fazem quase entusiastas da razão, procura os caminhos de uma outra sabedoria. Esta, sendo mais holística, calcada no respeito às leis eternas, procura

\begin{tabular}{|l|l|l|l|l|}
\hline Q Povista Dialectus & Ano 5 & n. 12 & Janeiro - Julho 2018 & p. 327-339 \\
\hline
\end{tabular}


conciliar natureza e cultura, justificando a expressividade saudosista, então, que a caracteriza. Ele sugere ser tocado pela simplicidade dos costumes existentes nos primeiros tempos na medida em que estes eram regidos por uma sabedoria divina que viabilizava a unidade, a inocência, a pureza, a tranquilidade, a igualdade, etc. Para o genebrino:

\begin{abstract}
Não se pode refletir sobre os costumes sem se comprazer com a lembrança da imagem da simplicidade dos primeiros tempos. É uma bela praia ornada unicamente pelas mãos da natureza, para a qual incessantemente se voltam os olhos e da qual com tristeza se sente afastar-se (OC III, Discours sur les sciences et les arts, 1964, p. 22).
\end{abstract}

Toda essa reflexão precedente, apesar de desconcertante, não deve causar dúvida quanto ao espírito iluminista de Rousseau no Primeiro Discurso (e nem no resto de sua obra). Ademais, o escrito não está reduzido a efetuação de um diagnóstico sobre as origens do mal, e nem unicamente em traduzir um pessimismo histórico que vai ser levado ao público. Daí é justificado seguirmos com o estudo do texto; tem-se mais elementos ainda - numa escrita que se constitui por dubiedades e antagonismos, fazendo-se um emaranhado de informações - dispostos para serem conhecidos e pesados.

Após introduzir a leitura com a posição de Rousseau onde defende a vida ativa do espírito e a busca incansável da virtude, tendo o contrapeso de seu ceticismo quanto aos caminhos traçados pela história, passo ao impacto que se vê causar em diversos âmbitos sempre que temos o homem em jogo no processo de civilização. $\mathrm{O}$ Primeiro Discurso discute, como disse antes, o problema do homem no comércio com a cultura, o conhecimento, e o progresso, entendendo que se tem, neste intercâmbio, efeitos na vida particular, e também na vida social, que atingem, em primeiro instância, o plano da moralidade, o qual trata daquilo que, na relação entre o ser humano e o âmbito citado - envolvendo isto, em especial, as ciências, as letras, as artes, a filosofia, a religião etc. - indica haver por consequência da ação tanto "vícios" como "virtudes". Pois: de que maneira o fenômeno cultural do "renascimento" na modernidade, visto sob o prisma moral, quer dizer, sob o ângulo dos hábitos, e dos costumes, contribui para produzir vícios ou gerar virtudes?

\begin{tabular}{|c|c|c|c|c|}
\hline Q Rovista Dialectus & Ano 5 & n. 12 & Janeiro - Julho 2018 & p. $327-339$ \\
\hline
\end{tabular}


No intercâmbio entre o homem e a cultura, sob o ponto de vista moral, no fomento das ciências e das artes, podemos pensar que é formado, definidamente, um conjunto de pares de opostos. De um lado, vê-se o fenômeno da frouxidão, da fraqueza física e psicológica, do efeminar-se, e identifica-se, de outro lado, a ativação do vigor, do espírito guerreiro, da coragem, do sentimento cívico, do amor à pátria. Sob tal perspectiva, é certo que há aquilo que se faz positivo e o que se constitui enquanto algo negativo. Para sabermos isso, temos de nos certificar sobre como Rousseau define virtude e vício no texto premiado em Dijon. Ele entende que virtude ora é força e vigor da alma, ora é prêmio, enquanto vício é fraqueza e também castigo. Em termos físicos, corporais, a força é proveniente, no sentido positivo, da nudez, da naturalidade; é resultante do abandono dos simulacros, da recusa do porte de máscaras. No sentido moral e psicológico, a virtude é emanada da inocência, da transparência, da unidade do sujeito consigo mesmo. Reflete-se ainda, aqui, a positividade no senso humano do dever, do civismo, do amor à pátria.

E o lado negativo sob a esfera moral, sabendo-se, como havia considerado Descartes no século XVII, que aquela, ou seja, a virtude, ou é ou não é ${ }^{4}$, sendo marcada pelo vício, é o contrário de tudo isso que mencionamos, quer dizer, revela-se com a moleza, a capacidade de dissimular, de pactuar com a falsidade, de mentir; mostra-se na limitação, igualmente, para resistir diante de todos os entraves, na perda da unidade e da coesão, na conivência, enfim, com os erros e com as vicissitudes.

Tratando a questão do fomento das ciências e das artes, agora, não do ponto de vista moral, mas pela esfera da ética, ocorre-nos perguntar em quais condições a liberdade individual é possível ou como dar-se-ia o oposto disso, ou seja, como se efetivaria o advento da servidão, da escravidão. Podemos supor, nesse âmbito, a instauração da autonomia humana a partir do texto rousseauniano? Antes não haverá uma liberdade original antepondo-se ao progresso? A referência à voz da consciência ao final do escrito e a respectiva atenção a ela não é um aspecto presente para intuir-se que a liberdade de cunho superior é alcançável? E o contrário desse plano elevado, ou do privilégio da condição original de contato só com a natureza, não será esta alienação ou

$4 \quad$ Na Carta a Princesa Isabel, Descartes assevera, dizendo algo quase parafraseado por Rousseau: "Há uma grande diferença entre as verdadeiras virtudes e as aparentes" (DESCARTES, R. A la Sérénissime Princesse Élisabeth, Première Fille de Frédéric, Roi de Bohême, Comte Palatin et PrinceÉlecteur de L'empire, in.: Éditions Gallimard, 1953, p. 553). Les príncipes de la philosophie, Oeuvres et Lettres, Paris,

\begin{tabular}{|c|c|c|}
\hline Rovista Dialectus & Ano 5 & n. 12 \\
\hline
\end{tabular}


letargia dado ao poder das ciências e das belas-artes? Não viveria o homem assim pelo fato de ser moldado para obedecer aceitando a opressão sofrida? Não é ele refém da excessiva resignação e do pendor de quem se deixa seduzir?

O homem experimenta, conforme o desdobramento do diagnóstico, o estado de quem se subordina à legislação eterna dos começos, fazendo-se naturalmente livre. Depois as ciências, as letras, e as artes aparecem, serenando-o diante da ação despótica dos governantes e de todos os artifícios, levando-o a amar sua escravidão.

Agora, na intenção de prescrever algo de positivo, visando a liberdade superior, o genebrino indica que a polidez, a civilidade, sobrepondo-se, cria os vícios indesejáveis, mas vale entender que teremos a virtude na simplicidade, conservando-se o homem na senda do bem, desde que ouça a voz da consciência, neutralizando o intercurso das paixões.

No que tange ao terreno "político" exclusivamente, nesta esfera da relação entre o homem e o renascimento das ciências e das artes, o Primeiro Discurso é mais tímido à primeira vista, contando com uma extensão menor. Mas Rousseau menciona o mal do despotismo, da atitude servil, da escravidão, da desigualdade, aspirando por leis melhores, mais justas, pela vigência de políticas mais honestas, sensíveis, mostrando-se estas em condições de contribuírem com a expansão da virtude e a instauração da liberdade civil. O pensador genebrino nota o quanto o poder político é importante e decisivo acreditando até que o saber e os intelectuais maiores muito dele poderiam tirar proveito. Aliás, nosso filósofo chega a elogiar os reis que protegeram as ciências, as letras, e as artes criando as academias e propondo os concursos literários (a exemplo deste de 1749), os quais são marcados por sua utilidade. Com isso, nós tivemos uma atenuação do mal e o indicativo de que a boa cultura pode ser efetivamente preservada, fomentada, disseminada, etc.

Por fim, com a meta de fechar essa parte de nossa reflexão, temos de tematizar a presença e o papel do fator econômico no comércio do homem com as ciências, as letras, e as artes após o renascimento na modernidade. Esse aspecto é exemplificado ora com o advento do luxo no ápice do processo de crescimento, ora com a instauração da miséria. Marcando sua polaridade, este último às vezes é mola propulsora do progresso, da indústria, da expansão comercial, mas às vezes, fazendo-se um objeto passivo, é consequência da injeção aplicada ao crescimento do saber no avanço da cultura, arcando com o prejuízo, portanto, da produção geral.

\begin{tabular}{|l|l|l|l|l|}
\hline Q Rovista Dialectus & Ano 5 & n. 12 & Janeiro - Julho 2018 & p. 327-339 \\
\hline
\end{tabular}


A teoria de Rousseau supõe a unidade e também essa viva tensão entre os diferentes aspectos e objetos. Ainda que isso seja existente, não somos autorizados a fazer uma leitura que apreende tais fatores como coisas unilaterais e estanques. Os quatro âmbitos indicados aqui, concedentes do caráter relativamente sistemático de nosso escrito, não passam de um artifício didático, pois as alternâncias e entrelaçamentos são visíveis. Wokler bem ilustra isso falando em "raízes políticas do vício" (1995, p. 22). Quer dizer, vício é algo de ordem moral, e o intérprete atribui-lhe uma fonte política, indesejada, aliás, para quem aprecia a existência de legitimidade no plano do poder.

Malgrado nossas considerações acima, a primeira parte do trabalho de Rousseau dá a oportunidade de pensar-se que o fator econômico é o que vem causar o mal no eixo político com a interveniência do luxo. Ou seja, este seria o responsável pela "dissolução moral" e pelo estabelecimento da "escravidão" sendo consequência dos "esforços orgulhosos" que realizamos para deixar o estado de ignorância feliz, representando, ao fim e ao cabo, um "castigo". E o "prêmio" estaria no caso, por sua vez, na simplicidade, na inocência, na liberdade natural, na igualdade, etc.

Observamos, por ora, que a desigualdade é um fator que ilustra o problema decorrente do luxo, ligando-se ao aspecto econômico, após figurar tanto na discussão moral como na reflexão sobre a política. Esse aspecto aparece implicado dessa forma, portanto, na questão do renascimento, movimento cultural europeu da modernidade, que é passível de ressalvas, como coisa benéfica no sentido absoluto, na visão de Rousseau. Enfim, como entender-se que alguém, nos dias de hoje, pode condenar o luxo, o requinte, a polidez, a civilidade, a riqueza, o dinheiro, como Rousseau o faz, logo no começo de nossos tempos? Por certo, se essas coisas indicam a elevação do Estado, elas ficam longe de serem tudo para o filósofo, pois sugerem a abertura do espaço para problemas diversos, indo do desequilíbrio da natureza, passando pelo esgotamento dos seus recursos, pela perversão moral, chegando às patologias de toda ordem, etc!

Perde-se muito da riqueza, e da substantividade, do Discurso em questão ao enfatizar-se seu caráter moral desconsiderando os aspectos que se relacionam ao âmbito econômico a partir do qual constata-se o incentivo da produção de todas as espécies sempre visando assegurar o lucro e garantir a posição hegemônica dos que desfrutam do poder, possuem muito dinheiro, etc. São esses homens, por este prisma

\begin{tabular}{|c|c|c|}
\hline Rovista Dialectus & Ano 5 & n. 12 \\
\hline
\end{tabular}


colocado, que impulsionam a evolução das ciências, das letras, e das artes, no interesse, em partes, de mantê-las como via de divulgação do progresso que desejam ver imperar. Essa presente ideia serve para melhor compreendermos o significado, no sentido mais amplo, da Renascença, e também a razão, no sentido mais específico, do desprestígio que começa a recair sobre a igreja católica enquanto instituição conservadora que trabalha freando o progresso, o qual chegava ao cume do seu desenvolvimento no século XVIII. Eis que escreve confirmando essa ideia o pesquisador Anderson: " $A$ opressora influência da Igreja Católica certamente era hostil de muitas formas ao progresso econômico" (1992, p. 12). Nesse quadro vê-se o recuo do feudalismo e a expansão do capitalismo, sendo o primeiro refratário à economia de mercado. Rousseau ainda que moderno e iluminista põe este último também em questão dado aos desequilíbrios igualmente gerados.

III

São esses desdobramentos que precisam, dentre outros, ser pensados e medidos na luz da argumentação do filósofo de Genebra, mas ao mesmo tempo visto sob a ótica do que conseguimos refletir 270 anos após a produção do texto no qual todos estes elementos, avaliados aqui rapidamente, são colocados enquanto objetos de análise e postos em pauta de discussão.

Da detecção do mal até indicar possíveis remédios, Rousseau oscila, no Primeiro Discurso, entre atender às exigências do concurso, falando da parceria que precisa haver entre o conhecimento e o poder, até abrir as portas para discussões mais amplas, capazes de serem levadas adiante em outros dos seus escritos. Busco apostar aqui que o mal e a indicação do remédio revelam-se no escrito, em sentido mais verticalizado, no apontamento da retomada da unidade, perdida na eclosão da dicotomia ser x parecer, conduzindo-o a indicar o valor de estudar-se o homem e a respectiva dificuldade que isso representa, algo que se repete, dada a força da tese, no Discurso sobre a desigualdade, como podemos notar, sacramentando o sentido e o caráter de minha formulação: "O mais útil e o menos avançado de todos os conhecimentos humanos parece-me ser o do homem e ouso afirmar que a simples inscrição do templo de Delfos continha um preceito mais importante e mais difícil que todos os grossos livros dos moralistas" (OC III, Discours sur l'inégalité, 1964, p. 122).

\begin{tabular}{|c|c|c|c|c|}
\hline Rovita Dialectus & Ano 5 & n. 12 & Janeiro - Julho 2018 & p. $327-339$ \\
\hline
\end{tabular}


Aqui estamos diante de um problema antropológico, mas também de uma questão ontológica, metafísica. Ultrapassar tal problema em termos práticos requer que se refaça o elo que fora rompido do qual decorrerá a paz, a harmonia, o contato mais íntimo do homem consigo mesmo, dando-se forma ao plano idealizado, seja no campo do agir, seja na esfera do fundamento ontológico, fechando-se com a conquista de uma estabilidade profunda e radical.

Estamos nesse momento, com a referida ruptura, diante da fonte de toda dor, a qual precisa ser neutralizada. E todo o projeto teórico-filosófico do autor vai no sentido de cumprir este ditame. ${ }^{5}$ Moral, ética, política, antropologia, economia, religião, pedagogia, ontologia, metafísica, coisas estas que se podem ver no contato com o Discurso sobre as ciências e as artes, participam do invólucro, do arcabouço intelectual e especulativo informados pela reflexão, que é muito distante, aliás, de algo banal e desprezível.

Mergulhados no drama do dia-a-dia, no trágico e cômico da vida, nós experimentamos toda a divisão entre o natural e o artificial. A civilidade, a vida no plano social e político, é composta por esta cadeia de dificuldades. Sair deste estado significa começar a reconhecer a unidade interna que nos caracteriza, e que fora perdida ${ }^{6}$, embora não aniquilada absolutamente, do coração humano, como é sugerido por Platão, no livro X da República, ${ }^{7}$ tornando justificada a ideia que sustentamos de que é sólido, amplo, e profundo o projeto teórico de Rousseau.

5 O eixo central do pensamento de Jean Starobinski e de Ernst Cassirer está radicado neste propósito razão pela qual eles são para nós aqui referências chaves. O também genebrino é certo do prejuízo que significa a fissura interna do ser humano. Para o caso próprio de uma referência específica ao Primeiro Discurso veja-se: STAROBINSKI, J. Jean-Jacques Rousseau; a transparência e o osbstáculo. cap. I, p. 15-18, conforme a edição brasileira, elencada na bibliografia. A lembrança do autor neokantiano, num projeto de igual natureza, é trazida à tona por Felix Heidenreich e Gary Schaal no pequeno livro Introduction à la philosophie politique publicado em 2012 na França por "CNRS Éditions" sendo tradução de um texto de 2009 saído na Alemanha.

$6 \quad$ Harald Höffding traz-nos o fragmento seguinte das Institutions politiques de Rousseau, fragmento este publicado por Steckeisen-Moulton antes de nós o reconhecê-lo no Emílio, onde indica a necessidade de recuperar-se a unidade: "Haced que el hombre vuelva a su unidad (rendez l'homme un!) y le habréis hecho todo lo feliz que puede ser" (ROUSSEAU apud HÖFFDING, H. Rousseau. Trad. de Fernando Vela, Madrid, Revista de Occidente, 1931, p. 138).

7 A República, segundo Pierre Aubenque, é "o mais amplo e o mais completo dos diálogos de Platão" onde ele "expunha sua teoria filosófica" notadamente "no quadro de uma reflexão sobre o Estado" (AUBENQUE, Pierre. A filosofia pagã, Vol. I. in.: CHÂTELET, François, História da filosofia; ideias, doutrinas, Trad. de Maria José de Almeida, RJ, Zahar, 1973, p. 167). Quero acrescentar, por minha conta, que Platão admite um pano de fundo servindo de alicerce da reflexão que seria justamente a questão da moralidade.

\begin{tabular}{|l|l|l|l|l|}
\hline Q Rovista Dialectus & Ano 5 & n. 12 & Janeiro - Julho 2018 & p. 327-339 \\
\hline
\end{tabular}


Com o Primeiro Discurso temos já elementos para pensarmos em reforma moral e política, indo um pouco além de um mero diagnóstico dos problemas. É projetado este ato de vasculhar o conjunto de possibilidades que parte da vida privada chegando ao âmbito da vida pública, sem afastar-se, portanto, o ar utópico e de romantismo. O filósofo sabe do valor de reencontrar-se a paz, o plano confortável tal qual se produz com a conduta aplicada pela natureza, retomando a capacidade de andarse com otimismo, fazendo o homem outra vez bom, generoso, e admirável, servindo enquanto modelo em sentido positivo, mas sem requerer o engajamento humano no sentido grupal, coletivo.

Vem a nós a imagem fornecida, ao final, pela exegese de Roche Kennedy que fala de Rousseau antes como um estoico, tocado sobretudo pelo pensamento de Sêneca, dado o efeito simbiótico causado na sua teoria política na medida em que sofreria fortemente o impacto desta sua fonte de leitura. Aqui, é dispensada a participação mais ativa do cidadão nos negócios públicos resultando um outro tipo de romantismo sendo o homem alvo de um resgate, extraído da obscuridade, pelo qual alcança a liberdade moral e a unidade. Mas experimenta isso sem viver pressões do todo, sem necessitar fazer-se um ente mais engajado. A essa última tarefa o nosso autor é bem verdade, termina, em partes, se dedicando, porém, tal realidade só acontece efetivamente com a escrita de Do contrato social.

\section{REFERÊNCIAS}

ANDERSON, M. S. La Europa del Siglo XVIII (1713-1789), Trad. de Ricardo Haas, México, Fondo de Cultura Económica, 1992.

DESCARTES, R. Lettre de l'auteur a celui qui a traduit le livre laquelle peut ici servir de préface, In.: Éditions Gallimard, 1953.

Les príncipes de la philosophie, Oeuvres et Lettres, Paris,

ENGELS, Friedrich. Anti-dühring; a revolução da ciência segundo o senhor Eugen Dühring, Trad. de Nélio Schneider, SP, Boitempo, 2015.

FERRARA, Alessandro. Modernity and Authenticity; a Study of the Social and Ethical Thought of Jean-Jaques Rousseau, New York, State University of New York Press, 1993.

HAMPSON, Norman. Histoire de la pensée européemne (4), Le siècle des lumières, Traduit de l'anglais par Françoise Werner et Michel Janin, Paris, Éditions du Seil, 1972.

MORIN, E. A construção da sociedade democrática após a queda do socialismo dito real e o papel da educação e do conhecimento para a formação do imaginário do futuro,

\begin{tabular}{|l|l|l|l|l|}
\hline Q Rovista Dialectus & Ano 5 & n. 12 & Janeiro - Julho 2018 & p. 327-339 \\
\hline
\end{tabular}


Trad. de Ester Grossi, Texto apresentado: Seminário Internacional Sobre Aprendizagem; Construtivismo Pós-Piagetiano, Porto Alegre/RS, 05 a 08 de dezembro, Promoção: UFRGS, PUC, GEEMPA e MEC, 1992.

ROCHE, Kennedy F. Rousseau; Stoic \& Romantic, Londres, Methuen \& Co Ltd., 1974.

ROUSSEAU, J.-J. Discours sur les sciences et les arts, Oeuvres Complètes, Paris, Éditions Gallimard, Bibliotèque de la Pléiade, Tome III, 1964.

Discours sur l'origine et les fondemens de l'inégalité parmi les hommes, Oeuvres Complètes, Paris, Éditions Gallimard, Bibliotèque de la Pléiade, Tome III, 1964.

WOKLER, Robert. Rousseau, Oxford, Oxford University Press, 1995.

STAROBINSKI, Jean. Jean-Jacques Rousseau; a transparência e o obstáculo, Trad. de Maria Lúcia Machado, São Paulo, Companhia das Letras, 1991.

\begin{tabular}{|l|l|l|l|l|}
\hline Rovista Dialectus & Ano 5 & n. 12 & Janeiro - Julho 2018 & p. 327-339 \\
\hline
\end{tabular}

